\begin{tabular}{c|c|c}
\hline \hline Vol. 1: 7-9, 2006 & ENDANGERED SPECIES RESEARCH & $\begin{array}{c}\text { Printed November 2006 } \\
\text { Published online February 3, 2004 }\end{array}$ \\
\hline \hline
\end{tabular}

\title{
Land and equipment
}

\author{
Otto Kinne* ${ }^{*}$ Jens Kunert, Waldemar Zimmermann
}

Inter-Research and International Ecology Institute Nordbünte 21 \& 23, 21385 Oldendorf/Luhe, Germany

\begin{abstract}
LAND
Located some $55 \mathrm{~km}$ south of Hamburg, Germany, our 'Inter-Research Land' is part of the community of Oldendor/Luhe. Its eastern border is the River Luhe. It covers about $55000 \mathrm{~m}^{2}$ (5.5 ha). For a schematic display consult Fig. 1.

Over thousands of years this wet-meadow area was formed and influenced by the meandering Luhe and its secondary or supplementary waters. Until about a century ago the Luhe valley supported a species-rich, intact wet-grassland ecosystem, harbouring a large variety of animals, plants and micro-organisms. Increasing agriculture activities caused significant changes. The farmers began to regularly distribute large amounts of liquid (and solid) manure over the land surfacemainly from cows, horses and sheep-in order to improve their harvest and to get rid of their waste products cheaply. They further modified the ecosystem by installing drainage or water supply systems, depending on their individual needs. Over many years the farmers mowed their grassland twice a year. In several cases they transformed their fields into cultivated areas for growing a variety of plants used as human food. In order to protect their fields from plant eaters, parasites and disease agents, they applied copious amounts of chemicals. At least several of these are known to negatively affect or even kill a large variety of animals, especially amphibians with their moist and sensitive skin.

Community officials, water engineers and technicians increasingly modified ('corrected') the Luhe's flow dynamics (see also Rund 2002) and in this way further contributed to ecological distortions.

After acquiring the land we attempted to restore, as much as possible, original ecological conditions. We put an end to fertilisation activities, chemical treatments and regular low-cut mowing. It turned out to be necessary to invest several years of hard work in order to control plants, especially stinging nettles Urtica dioica ('Brennessel'), that were thriving immensely on the nutritionally enriched ground.
\end{abstract}

*Email: kinne@int-res.com. Fax: +4941328883
We searched for additional water sources and were lucky to hit on 2 artesian wells. These have now already benefited our research efforts over several years and fortunately do not show any signs of performance reduction. We built ponds, pools, ditches, mounds, slopes, over-wintering quarters for amphibians, especially toads and newts. We bought and positioned nesting sites for birds and created shelters for bats. And we constructed and equipped 2 small field laboratories. They are a most important prerequisite for breeding, rearing and raising offspring of toads and newts and thus for supporting the re-establishment of viable field populations.

\section{EQUIPMENT}

Tools. We have a well-equipped workshop, a microscope, a binocular microscope and a variety of generally used simple laboratory tools. And we have waterand ground-management equipment, as well as storage rooms and roofed-in storage areas (for pumps, pipes, hoses, stones, plates, cement, wood, sand, gravel, etc.). All in all, the tools are modest and the working capacities rather limited.

Culture systems. As culture containers we use both commercially available and self constructed products. In the field we built, and continually improved, several types of culture devices (enclosures) and artificial habitats. They will be described in forthcoming reports.

Laboratory facilities. Consisting of glass or plastic, our experimental laboratory containers vary in construction and size. They will be described and illustrated in later reports. Most containers are covered by easy-to-remove plastic lids accommodating built-in light sources and accesses (removable openings) for feeding, aeration and filtering. Other lids are covered by gauze. Electricity outlets are either permanent or timer-controlled and thus allow for changes in day length. All electrical cables are surrounded by grounded mesh to avoid undesirable electromagnetic side effects. We use bulbs proved to be effective and

\footnotetext{
${ }^{\star}$ First published April 14, 2003, under INTER-RESEARCH REPORTS as Rept 2
} 


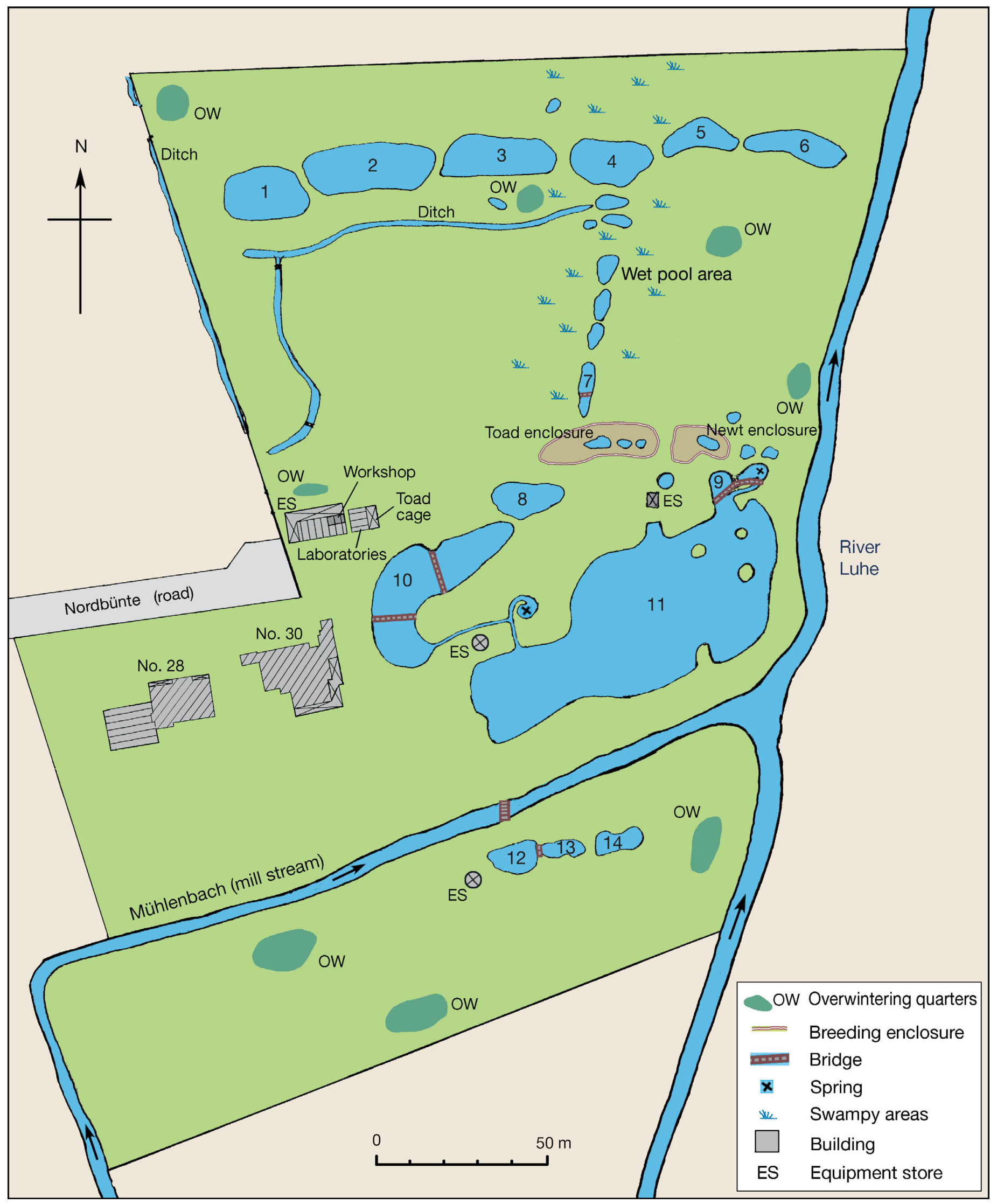

Fig. 1. IR Land. Schematic display. 1 to 14: ponds. Pools are not numbered; mounds and slopes are not shown 
safe in the pet fish industry. Natural daylight can enter through windows and the temperature in the rooms can be controlled.

The culture containers are filled with water collected from our ponds and filtered to keep out potential predators, such as leeches and insects. Before use we leave the mildly aerated and fully illuminated containers undisturbed for about 3 weeks and thus allow a film of micro-organisms to develop on their walls and bottoms.

Fertilised eggs are collected from our ponds or breeding containers. Usually we place 80 to 100 eggs in one container and maintain them at temperatures between 18 and $23^{\circ} \mathrm{C}$ under mild water aeration. Details on breeding and raising will be presented in forthcoming reports.

Field facilities. Over the years we have constructed, tested and improved several enclosures in which our animals can find natural food, are protected from predators (e.g. birds, cats, mice, rats) and are restricted in their migratory activities. Examples of these constructions will be detailed in later reports.

Our animals, especially the toads, are masters in escaping any attempts to restrain them. Their built-in drive to expand and conquer new territories are simply 'out of this world'. And so are their inventive abilities to find answers to our plots to restrict them.

A story will document these statements. Adjacent to our labs we had built a toad cage (ca. 7 by $7 \mathrm{~m}$ and about $2.3 \mathrm{~m}$ high). It was completely enclosed by wire mesh of a size that, according to tests, would prevent any adult toad from escaping. The mesh totally covered the confinement: sides, top and $120 \mathrm{~cm}$ below ground (to prevent attacks from underground predators). In order to entirely exclude escape we covered the lower parts of the above-ground confinement insides with plastic plates, $120 \mathrm{~cm}$ high, and topped by inverted gutters. As far as we could see, escape was entirely impossible.

Before introducing the toads we made a last check. Surprisingly we noticed a sudden water motion in one of the small pools we had installed. When the water moved again we caught the actor: an adult toad that had entered our confinement from the outside! The toad had escaped from an aquarium in our housekeeper's first-floor apartment several hundred meters away (we can identify individual toads by their belly colour patterns). The aquarium was covered by a glass plate, but obviously one day the plate was, after 2 years of no toad escape, not completely covering the aquarium. The toad was reported missing for several days before turning up in our newly built confinement. Acknowledging the toad's fantastic performance we released it in IR Land. After making itself heard (it was a male) for about 2 weeks, there was complete silence. The toad appeared to have disappeared. Until ... the housekeeper's wife, standing below the balcony, from which the toad must have jumped down on its way to freedom, looked down and noticed the toad sitting on her right shoe. Since the toad had decided in favour of its home, where food and protection were guaranteed, it was returned to the aquarium whose lid received more attention now than before.

Later, we introduced some 20 red bellied toads into the toad cage and thereafter enjoyed a readily reproducing toad population for 2 years. The population provided a total of 242 juveniles which we distributed in IR Land. But after the 2 years all toads suddenly decided to emigrate. How they managed to escape we do not know to this day!

\section{LITERATURE CITED}

Rund C (2002) Der Heidefluss Luhe und ihre Aue - Auswirkungen der Besiedlung. In: Oldendorf/Luhe. Eine Dorfchronik. Community of Oldendorf, Oldendorf, p 37-51

\section{ENDANGERED SPECIES RESEARCH}

Number 3: Breeding, rearing and raising of Bombina bombina

Number 4: Successful re-introduction of the newts Triturus cristatus and T. vulgaris 